\title{
Unmet basic needs and family functions gaps in diabetes management practice among Indonesian communities with uncontrolled type 2 diabetes: A qualitative study
}

\author{
Rian Adi Pamungkas, Kanittha Chamroonsawasdi, Andi Mayasari Usman
}

Adi Pamungkas R, Chamroonsawasdi K, Usman AM. Unmet basic needs and family functions gaps in diabetes management practice among Indonesian communities with uncontrolled type 2 diabetes: A qualitative study. Malays Fam Physician. 2021;16(3);23-35. https://doi.org/10.51866/oa1123

\section{Keywords:}

Unmet need of family

function, diabetes mellitus,

self-management, Indonesian

communities

\section{Authors:}

\section{Kanittha Chamroonsawasdi \\ (Corresponding author) \\ Ph.D., RN}

Department of Family Health, Faculty of Public Health, Mahidol University Bangkok, Thailand

Email: kanittha.cha@mahidol.ac.th

\section{Rian Adi Pamungkas}

Dr.P.H., Ns

Department of Nursing, Faculty of Health Sciences, Esa Unggul

University, Jakarta, Indonesia

Email: rian.adi@esaunggul.ac.id

Andi Mayasari Usman

M.Kep., Ns

Department of Nursing, Faculty of Health Science, Nasional University Jakarta, Indonesia

\begin{abstract}
Family members play a vital role in both helping and undermining diabetes mellitus selfmanagement practices. This qualitative study aimed to explore the potentially unmet needs of family function to support diabetes self-management (DSM) practices. In-depth interviews and focus group discussions (FGDs) were conducted among different key informants, including uncontrolled T2DM patients, caretakers and healthcare providers (HCPs) at community health centres. An open-ended approach was applied to elicit responses from the key informants. A total of 22 participants were involved in this study. All interview and FGD processes were audiorecorded and transcribed verbatim. The results found that all key informants addressed six core themes, with sub-themes to describe the unmet needs of family function to support DSM practice. The critical unmet needs of family function include: 1) Lack of problem-solving skills to deal with poor diabetes management; 2) Ineffective communication and refusal to share the burden of diabetes management; 3) Lack of affective responsiveness to encourage patients' compliance; 4) Lack of affective involvement in DSM; 5) Insufficient family roles in supporting patients; 6) Poor behaviour control of T2DM. Our findings provide insights into how family function may influence the adoption and maintenance of healthy behaviours among diabetic patients. Since health providers seek new approaches to improve DSM practices, this valuable finding was essential to understand how family function can improve and empower patients in DSM practice.
\end{abstract}

\section{Introduction}

Uncontrolled type 2 diabetes mellitus (T2DM) has become a significant challenge for Indonesia's public health system. More than 10 million people in Indonesia were reported to be living with T2DM. Notably, most of them had not met their glycaemic control target goals, which can cause diabetes complications such as neuropathy, nephropathy, retinopathy and cardiovascular disease. ${ }^{1}$ Self-management practices are required to control healthy behaviours and prevent severe complications among uncontrolled T2DM patients. ${ }^{2}$

Diabetes self-management (DSM) requires patients to reconcile their resources, values and preferences with a healthy diet, being actively involved in physical activity, avoiding cigarette and alcohol consumption, adhering to medication, monitoring blood glucose levels and preventing diabetes complications. ${ }^{3,4}$ Family members can serve a vital role in helping and reminding patients about their self-management practices. ${ }^{5}$ Family function is a fundamental concept linked to providing appropriate tasks that improve the capacity of patients and their family members in dealing with problems, preventing the misinterpretation of emotional responses and maintaining DSM behaviours. ${ }^{6,7}$

Although several studies have shown the positive effects of family function by involving and supporting patients in achieving positive health outcomes, there remains a research gap in Indonesia regarding how family members should perform the family function to help diabetic patients in their DSM practices. ${ }^{8}$ Family members are necessary for DSM practices, especially in lifestyle modification. ${ }^{9,10}$ Also, family members improve patients' efforts in managing chronic conditions such as diabetes. ${ }^{11}$ However, previous studies have not applied the six components of family 
function theory to support DSM practices. The element of family function is essential and covers all of the patients' needs. In the rural context of Indonesian communities in West Sulawesi, this study aimed to explore the potentially unmet family function needs of T2DM patients related to supporting DSM practice. The findings from this study should provide a greater understanding of the local community contexts that may influence family function supporting T2DM patients in daily life activities and will also be used as baseline information for healthcare providers to strengthen family involvement in DSM.

\section{Research Questions}

1. What is the current situation of family functioning to support T2DM patients in DSM practice?

2. What are the unmet needs of T2DM patients in terms of their family functioning to support DSM?

\section{Literature Review}

This literature review covers three main areas: 1) The concept of family function in supporting DSM practice; 2) The daily life contexts of T2DM patients in Indonesian communities; 3) The problems faced by family members when supporting T2DM patients in their DSM practices.

Concept of family function in supporting DSM practice

Family function is classified into two main types: result-oriented and processoriented. ${ }^{12}$ The result-oriented type is also known as Olson's circumplex model, which defines the family system and divides its role into three features, which include family intimacy (the relationships between family members), family adaptability (changes to the family in terms of its power structure, roles and ability to cope with the external environment) and communication between family members. ${ }^{13}$ The process-oriented (also known as McMaster) theory describes family function based on the ability to perform the tasks that families need to complete. ${ }^{14}$ The latter concept classifies family function into six basic tasks, which include problem-solving (to eliminate the functional capacity problems of the family), communication (information communication between family members), family roles (behavioural patterns of family members to complete family functions), affective response (emotional response to stimuli), affective involvement (concern and attention between family members) and behavioural control (freedom of family members in family activities). The McMaster family function concept is widely used to explain the family system and its function to maintain family equilibrium through the mutual relationships between family members. ${ }^{15}$

Family function and family roles are not homogeneous. Instead, they are complex and based on family members' expectations of support for T2DM patients performing their DSM practices. ${ }^{16,17}$ To achieve the positive effects of family members supporting DSM, family members should perform their respective functions to achieve the demands of care for T2DM patients. ${ }^{18}$ A previous study applied the notion of family function in supporting DSM practice. In that study, family members' roles were crucial to assisting the patient in dealing with his crisis. ${ }^{19}$ Another study also applied communication skills and family involvement as two parts of the family functioning process in diet management, medication adherence and blood glucose monitoring. ${ }^{18}$ Furthermore, an additional study revealed a positive effect of family function in decreasing HbA1c levels. ${ }^{20}$ Moreover, another study was conducted to empower family members to support the patients in their DSM. The findings of these studies highlight the positive impact of family empowerment on health outcomes. ${ }^{10}$

In the DSM approach, the use of family function is a positive way to provide appropriate roles and responsibilities for family members in supporting DSM practices. In this study, six dimensions of family function based on McMaster's family functioning theory were included: 1) problem-solving; 2) communication; 3) affective response; 4) family role; 5) family involvement; 6) behaviour control. These were used to explore how family function influenced DSM practices and related to unmet needs since low-income family function could result in poor glycaemic control. A better understanding of family function could clarify how to help both persons with T2DM and their family members maintain proper DSM to improve glycaemic control. $^{21}$

A previous study focused on family involvement to reduce blood glucose levels among diabetic patients in Indonesia found 
that the effective participation of the family caretaker can facilitate proper glycaemic control among T2DM patients. ${ }^{22}$ The present study aimed to apply a family function concept to help patients improve their health outcomes.

\section{Daily life context of diabetic patients in Indonesian communities}

Indonesia is a patriarchal society. The constructs of culture and religion influence this, with traditions being taught through both formal and informal education. Indonesian people in West Sulawesi follow traditional family lifestyles. These traditional practices are closely linked to the local context of people. Family members play an essential role in decision-making at the household level, especially regarding aspects related to the health of other family members. ${ }^{4}$

The majority of the Indonesian community still follows the conventional method of sharing meals among all family members. Typically, most of them prepare food by themselves. However, on some traditional occasions, they gather to prepare various types of food and eat together. This situation becomes a challenge for diabetic patients since they must follow their DSM in terms of dietary control.

Problems related to family members supporting T2DM patients in their DSM practices

Family members serve essential roles in promoting healthy lifestyle behaviours and appropriate emotional responses, sharing feelings and supporting sustained DSM practices. However, in certain situations, family members believe that their lifestyle changes should depend on their own decisions due to difficulties related to sharing knowledge on diabetic control with their family. ${ }^{23}$ Although some families support patients in their DSM practices, they often sabotage or undermine patients' self-care efforts by providing unhealthy meals and tempting patients to eat sweets as a reward they fully comply with their medications. ${ }^{24}$ These actions may become harmful and often conflict with established family routines. Therefore, to achieve optimal DSM practices without harm and conflict, a family-based approach is required for this population. This study aimed to improve health service delivery by applying the effective management of DSM practices through involving family members as critical support for glycaemic control among T2DM patients.

\section{Material and Methods}

\section{Study design}

Qualitative research using a phenomenological study was conducted to explain and interpret the meanings of individual experiences based on perspectives and perceptions within the local context. ${ }^{25}$ T2DM patients were a primary source of data collection. More specifically, the data include the meanings and perceptions of the key informants regarding their family functioning to support DSM practice. Furthermore, the unmet needs of T2DM patients due to poor family function, problems and challenges in daily activities were also collected. A wide range of themes and sub-themes were related to the unmet family function needs of these patients. For different perspectives, insufficient family roles in DSM practices among low-income families, the patients, their caretakers and their healthcare providers (HCPs) were also added. This study represents the preliminary phase of a sequential exploratory mixed-method design to explore the current situation of DSM practices and family function in supporting T2DM patients in glycaemic control. The findings were used to design intervention activities to strengthen the family function in the later phase.

\section{Study setting}

The qualitative study was conducted between 1st January and 28th February 2019 at the community health centre located in Polewali Mandar District, West Sulawesi, Indonesia. This community health centre provides essential services to communities, including medical facilities, immunisation, geriatric services and endocrinology.

\section{Samples and inclusion criteria}

The triangulation method was used to explore data from different viewpoints among patients, family caretakers and HCPs. The triangulation method is widely used in qualitative studies ${ }^{26}$ to assemble an aggregation of data collected from different sources or the different viewpoints of key informants to validate the findings' truth. Also, multiple data collection methods and the use of different perspectives among the researchers in data analysis can be used to gain a greater understanding of a particular phenomenon.

A total of 22 key informants were recruited based on the inclusion criteria. These included 
eight uncontrolled T2DM patients, eight family caretakers and six HCPs.

As the primary key informants, the patients were recruited from the Prolanis members of the diabetes control programme at the community health centre. This programme was launched in Indonesian communities to promote effective diabetic prevention and control via regular home visits performed by HCPs to monitor DSM and blood glucose. The inclusion criteria were as follows: 1) Uncontrolled T2DM with an $\mathrm{HbA1c}$ level $>6.5 \%$; 2) $\geq 35$ years of age; 3) Has been living with T2DM for at least 2 consecutive years; 4) Able to communicate in the Indonesian language and willing to share ideas and experiences via an in-depth interview process. The patients were excluded if they had severe complications that required hospitalisation. Before data collection, the research team conducted a meeting with the HCPs at the community health centres to explain the data collection objective. Then, the primary key informant group was recruited and the researcher made appointments to visit each patient in their home for an in-depth interview. Among the primary key informants, 12 were recruited from six communities. Overall, eight informants agreed to participate in the in-depth interview process after informed consent was obtained. The second key informant group comprised the caretakers directly related to T2DM patients, which consisted of either the wife, husband, daughter or son responsible for serving as the primary caretaker and supporting the patient in daily life activities and DSM practices. The selection of caretakers was performed in parallel with the T2DM patients after providing a clear explanation of the study objectives. Family members were excluded if they had no experience in taking care of patients with diabetes mellitus, were unwilling to participate in this study or were not living in the same house as the patients.

The inclusion criteria for the HCPs included those whose role was to provide diabetes care and support at the community health centre and those who had worked in this area for at least 1 year. We recruited one HCP from each of the six different community health centres in Polewali Mandar District. Before the indepth interviews and focus group discussions (FGD) were carried out, informed consent was obtained and the confidentiality of information was clarified. Moreover, the presentation of our findings would not directly outline the personal information of each key informant.

The main themes were developed based on the six aspects of family functioning theory: 1) Problem-solving related to improper DSM practice; 2) Effective communication to strengthen DSM practices and remind patients about blood glucose monitoring and medication adherence; 3) Affective response through empathy and sharing love and care; 4) The family role providing support in DSM practices (e.g., providing healthy food, accompanying patients for doctor visits and encouraging patients to exercise); 5) Family involvement in daily activities for glycaemic control; 6) Behavioural control of the patients to promote the reduced consumption of sweets and unhealthy food, adherence to the medication and monitoring of blood glucose.

Details regarding the key informants, data collection methods and data collection themes based on the triangulation method are summarised in Table 1.

Table 1. Description of samples based on the triangulation method.

\begin{tabular}{l|l|l}
\hline Participants & Methods & Themes \\
\hline $\begin{array}{l}\text { Uncontrolled T2DM } \\
\text { patients }(\mathrm{n}=8)\end{array}$ & In-depth interview & $\begin{array}{l}\text { - Perception of family function support and unmet } \\
\text { needs in DSM practices from caretakers } \\
\text { Challenges and obstacles of patients in performing } \\
\text { DSM practices }\end{array}$ \\
\hline Family caretakers $(\mathrm{n}=8)$ & In-depth interview & $\begin{array}{l}\text { - Family function to support patients in their DSM } \\
\text { practices } \\
\text { Challenges and obstacles to supporting patients in } \\
\text { their DSM practices }\end{array}$ \\
\hline $\begin{array}{l}\text { Healthcare providers } \\
(\mathrm{n}=6)\end{array}$ & Focus group discussion & $\begin{array}{l}\text { - Implementation of existing services to support } \\
\text { patients and their families in DSM practices at the } \\
\text { community level }\end{array}$ \\
\hline
\end{tabular}




\section{Data collection procedure}

The researcher and research assistants were trained on the qualitative method of data collection and the roles of note-taking and tape-recording. In-depth interviews and FGDs were conducted using a semi-structured interview format with open-ended questions and followed an interview guideline based on the main themes and sub-themes to elaborate the information based on their viewpoint. Each interview was conducted for approximately 60 to 90 minutes in a private room. Before conducting in-depth interviews and FGDs, all participants signed an informed consent form. The researchers also kept participants identities confidential to ensure privacy.

All data were audio-recorded and transcribed verbatim by two researchers. The interview guideline included the following themes: 'background information', 'unmet need in family function perceived by T2DM patients', 'family function to support DSM practice', 'responsibilities in diabetes management', 'challenges in DSM' and 'challenges in supporting T2DM patients in DSM'. The interview guideline was developed by researchers based on the concept of family function and the DSM model. Then, each question was checked by three experts to ensure the content validity of the interview guidelines. Inappropriate questions were modified by the researchers based on the experts' suggestions. A pilot test was also conducted among three uncontrolled T2DM patients and three caretakers from the same families as the patients.

Bracketing interviews were conducted prior to, during and following the data collection process to uncover themes and sub-themes that may hinder the researcher's ability to listen to the respondents or trigger emotional responses amongst participants while interviewing with the researcher. These were also used to clarify the key informants' experiences by exploring their forgotten or recalled experiences.

Two researchers analysed the data saturation after all data were transcribed from the audio recording to the answer sheet. The involvement of participants was required to check the transcripts of the interviews. All information from the key informants that represented a new viewpoint was triangulated by comparing the critical point or information. Two researchers extracted and quoted key themes and sub-themes from different data sources in parallel to reach a consensus on the findings.
Comprehensive data management is crucial to protecting the study participants. In this process, we defined data boundaries and protections that adhere to ethical standards while prioritising data dissemination. Dissemination of the results rests upon the ability to collectively determine how, where and to whom a team would like to communicate the results. In this process, we selected salient themes, which were then analysed and reported on through descriptions of the aggregated data in the local contexts.

To address credibility, the researchers attempted to reveal an accurate picture of the phenomenon under scrutiny. To facilitate transferability, we provided sufficient details regarding the fieldwork contexts to decide whether the prevailing environment was similar to another situation. Finally, to achieve confirmability, the researchers took steps to demonstrate that findings emerged from the data and not their predispositions.

\section{Data analysis}

The data were transcribed and provided verbatim from the audio recordings. Two researchers reviewed and read each transcript and grouped the interpretations and meanings from their emic viewpoint into main themes and sub-themes to elaborate the phenomena. The summary of the transcript was scripted to track the different key themes. The final step in this qualitative data analysis was to summarise the categories of critical themes and subthemes based on each group of key informants' viewpoints.

\section{Ethical considerations}

We obtained informed consent from all participants who were willing to participate in this study. The Ethical Review Committee for Human Research, Faculty of Public Health, Mahidol University approved this study (number: MUPH 2018-173). A permission letter from the head of each community health centre was also obtained before conducting this study.

\section{Results}

\section{Demographic characteristics}

We recruited and interviewed eight uncontrolled T2DM patients. The average patient age was 45 years. Out of eight patients, three were male and five were female. Their duration of illness ranged from 2 to 7 years. Some T2DM patients received support from their spouse, daughter 
or another family member. Seven of the family members included in this study were female and one was male. Most of the family members had completed high school and received a bachelor's degree.

Most of the HCPs that participated in this study were female. Three of them had completed a level II diploma in nursing, whilst the other three had graduated with a bachelor's degree. The HCPs had been working in the Prolanis programme, which mainly responded to the diabetes care units at community health centres.

Diabetes mellitus self-management practices Within the community health centre, diabetes management has primarily occurred in the form of primary healthcare services. Patients with diabetes mellitus were required to perform healthy behaviours to control blood glucose levels. However, some barriers to DSM were identified among the T2DM patients, such as unhealthy eating habits, a lack of physical activity, loss to follow-ups, and a lack of blood glucose monitoring.

Some barriers within the key informants' families regarding the support of diabetes selfmanagement practices also existed. Conflict within the family also became a barrier to effective DSM practice. For example, they separated food for the patients during meals with other family members. Moreover, the family members sometimes sabotaged the patients by being strict about food, which caused some conflicts within the family. Therefore, exploring the needs of the patients regarding their DSM practices was a crucial point in this study.

Unmet needs of family functioning to support diabetes mellitus self-management practices

Following the components of family function, the unmet needs of T2DM patients in terms of family functioning to support diabetes mellitus self-management (DMSM) practices were systematically described by the lowincome family function, which could not serve their needs in DMSM practices. This was categorised into the following themes:

\section{Lack of problem-solving skills to deal with poor diabetes management}

Five patients lacked decision-making skills to deal with problems that occurred whilst maintaining their DMSM practices. Some patients revealed that their caretakers did nothing to help them think about the problem because they lacked an understanding of diabetes and its management. Additionally, the caretakers also lacked critical thinking and problemsolving skills when faced with the poor self-management of T2DM patients. Other patients mentioned that they lacked skill and support and had personal conflicts with family members, especially when family members asked them to avoid unhealthy food.

If I am feeling stressed and having difficulty falling asleep at night, my husband tries to support me-but it is difficult to do' (Patient no. 2, female, 41 years old).

Sometimes we have conflicts when she forbids me from eating certain foods, such as meatballs and soft drinks' (Patient no. 8, male, 55 years old).

Five family members also expressed some difficulties related to solving patients' problems. Some of them did nothing when patients faced the problem of uncontrolled glycaemia. Notably, some family members mentioned their conflicts with patients when they asked them to avoid junk food, reduce fatty and sweet food intake and recognise their portion size.

I sometimes advise and help them to control the diet of my husband, but he always conflicts with me when I forbid him from eating certain foods. I do nothing when my husband is angry with me' (Wife, 50 years old).

Three HCPs reported that most caretakers do not understand how to care for patients with T2DM and lack the skills required to support patients in coping with diabetes. They also mentioned that caretakers lacked skills for dealing with patients' problems and were unclear about early detection and how to help patients when they complain about their condition.

Some of the family members lack the knowledge and skills needed to care for their families, and they also experienced difficulty in helping patients when they complain about their disease' (HCP no. 1, female, 30 years old). 
2. Ineffective communication and refusal to share the burden of diabetes management Four patients mentioned a lack of effective communication with their families about diabetes and its' management. One patient discussed daily activities rather than a discussion about their diabetes and health condition. Another patient said that she rarely discussed it with her husband since he was busy working. Two patients expressed the same event of not consulting their families because they should take care of themselves.

I rarely communicate with my husband about my disease because I should be responsible for my body' (Patient no. 2, female, 41 years old).

'Almost every day, my husband goes to work. So, I rarely communicate or discuss my condition' (Patient no. 5, female, 63 years old).

Some family members also reported a lack of positive communication with patients. They refused to share the burden with the patients and discouraged patients from discussing their problems. One family member said that she gave a patient money to check their blood glucose and visit the community health centre for follow-up treatment due to a lack of time to take care of and accompany the patient to see the doctor. Other family members expressed their negative feelings when discussing diabetes with family members because there were some conflicts.

'I seldom communicate with my wife about the disease. However, I just give her money when she needs to check her blood glucose at Puskesmas' (Husband, 63 years old).

3. Lack of affective responsiveness to encourage patients' compliance

Five patients reported that they received inadequate responses to their conditions. Both patients and their caretakers often had personal conflicts, whilst the caretakers felt unhappy and angry when the patients ignored their advice.

'We often have a conflict between us because she cooks food without tasting it and sometimes my family gets angry with me when I complain about that food' (Patient no. 8 , male, 55 years old).
One family member remained silent whilst ignoring and discouraging a patient from discussing her condition. One spouse prepared unhealthy food and expressed irritation and doubt about food choices.

'Sometimes I don't care about the patient when he does not follow my advice and feel discouragement because he refuses my suggestions and the doctor's advice' (Wife, 50 years old).

\section{Lack of affective involvement in diabetes} management

Three patients managed their selfmanagement practices without their families becoming involved. One patient said that her husband just provided some money without affecting the diabetes management process. The two remaining patients also mentioned that they managed their diet by themselves because their family members were not free and had to work every day.

'The decisions regarding my treatment are dependent on me; I manage everything by myself. My husband just gives me money when I need to do a check-up at the hospital' (Patient no. 3, female, 55 years old).

'I always prepare my menu by myself since my family must go out to work' (Patient no. 8, male, 55 years old).

Contrary to other family members' perspectives on managing diabetes, treatment should be the responsibility of the patient. Another family member said although he was not involved in the patient's treatment plan, he supported its financial needs. One family member mentioned that the patient was more active in seeking diabetes information, so he only provided some money to address the patient's needs. Also, another family member expressed her feelings about conflicts with the patient when discussing diabetes and its management, which ultimately led her to ignore it.

'My wife is more active in seeking information regarding diabetes management. I just provided some money' (Husband, 63 years old). 
'Sometimes, I have conflicts with my husband when discussing diabetes and its management. Therefore, I ignore my husband when he is angry with me' (Wife, 50 years old).

Some HCPs mentioned that most patients come to community health centres for health check-ups without family members. They come for routine blood glucose monitoring and sometimes join a group for aerobic exercise.

I have seen many patients come to community health centres alone for routine blood glucose level checks. They also join aerobic exercises, take medication and receive education in Puskesmas' (HCP no. 6, female, 35 years old).

\section{Insufficient family roles in supporting the patients}

Five patients said that they find it difficult to solve problems and receive suboptimal support from their family members. Some patients solve issues by themselves since family members do not understand diabetes and its self-management. In contrast, one patient experienced conflict whilst implementing DMSM practices. Other patients expressed their feelings regarding difficulties they faced in managing portion size, avoiding sweet and fatty foods and preparing healthy food to eat without any support from their relatives.

I have had difficulty controlling my diet, especially when attending some special occasions. I ate all kinds of food-my husband was not worried about that' (Patient no. 3, female, 55 years old).

'When I become bored, my family allows me to eat all kinds of food' (Patient no. 3, female, 41 years old).

Two family members said that they sometimes had conflicts with the patients because they did not follow the dietary control menu plan for T2DM. Moreover, patients faced challenges when attempting to follow the dietary regimen since they always ordered food from a restaurant.

'We have difficulties in controlling food because we often order food from the restaurant' (Family member, male, 55 years old).

\section{Poor behaviour control}

Most patients faced some difficulties in controlling their behaviours. They felt dull and uncomfortable, especially in certain conditions or when staying away from home.

I face difficulty in controlling my diet, especially when attending wedding ceremonies' (Patient no. 1, female, 48 years old).

'My wife never reminds me to control my diet when I am far away from home' (Patient no. 8, male, 55 years old).

This is inconsistent with family members' perceptions of difficulties in controlling blood glucose levels when they were not staying with the patients. Some of them reminded the patients to be aware of accidents due to falling when wearing slippers and how to wear comfortable slippers to prevent foot ulcers.

'I am trying to control my mom's blood glucose level but finding it challenging, especially during special occasions. I always suggest that she maintains her blood glucose level, but she is bored of doing it (Family member, female, 38 years old).

'I face difficulty in controlling my husband's diet when he is far away from home. I often remind him to take care of his foot ulcer by using comfortable slippers (Family member, female, 45 years old).

One healthcare provider mentioned that most patients and their family members faced difficulty in maintaining blood glucose levels within the normal range, especially when they did not follow advice from healthcare providers regarding a healthy diet and regular exercise.

'When I interview some patients and their caretakers, most of them find it difficult to control and maintain blood glucose in the normal range. Their blood sugar is unstable and sometimes higher than normal, especially when ignoring diet and inactive physical activity' (HCP no. 2, male, 34 years old).

Table 2 summarises the unmet needs of family function in supporting DMSM practices. Six themes were identified from this 
study: 1) Lack of problem-solving skills to deal with poor diabetes management; 2) Ineffective communication and refusal to share the burden of diabetes management; 3) Discouragement and feeling irritation about patients' compliance; 4) Uninvolved in decisions related to diabetes management; 5) Insufficient family roles in supporting patients; 6) Inconsistent management of healthy behaviour during special occasions.

Table 2. Unmet needs of family function in DMSM practices.

\begin{tabular}{|c|c|c|}
\hline Themes & Sub-themes & Sources \\
\hline $\begin{array}{l}\text { Lack of problem-solving } \\
\text { skills to deal with poor } \\
\text { diabetes management }\end{array}$ & $\begin{array}{l}\text { - Lack of knowledge and skills to solve the problems } \\
\text { - Conflict between the patients and caretakers } \\
\text { - Obstacles to providing family functions to support } \\
\text { DSM practices }\end{array}$ & $\begin{array}{l}\text { - Patients } \\
\text { - Family caretakers }\end{array}$ \\
\hline $\begin{array}{l}\text { Ineffective } \\
\text { communication and } \\
\text { refusal to share the } \\
\text { burden of diabetes } \\
\text { management }\end{array}$ & $\begin{array}{l}\text { - Poor communication to support DSM practices from } \\
\text { the family } \\
\text { - Discouragement and feeling inadequate about } \\
\text { communicating and discussing with family } \\
\text { - Lack of time to perform positive communication }\end{array}$ & $\begin{array}{l}\text { - Patients } \\
\text { - Family caretakers }\end{array}$ \\
\hline $\begin{array}{l}\text { Lack of affective } \\
\text { responsiveness to } \\
\text { encourage patient } \\
\text { compliance }\end{array}$ & $\begin{array}{l}\text { - Self-management practices without family support } \\
\text { - Refraining from involvement in supporting patients } \\
\text { with DSM } \\
\text { - Poor judgement related to DSM since patients are } \\
\text { responsible for taking care of themselves }\end{array}$ & $\begin{array}{l}\text { - Patients } \\
\text { - Family caretakers }\end{array}$ \\
\hline $\begin{array}{l}\text { Insufficient family roles } \\
\text { in supporting patients }\end{array}$ & $\begin{array}{l}\text { - Insufficient family support on healthy behaviours } \\
\text { - Feeling difficulties in managing a healthy diet } \\
\text { - Conflict with patients on dealing with diet control }\end{array}$ & $\begin{array}{l}\text { - Patients } \\
\text { - Family caretakers }\end{array}$ \\
\hline Poor behaviour control & $\begin{array}{l}\text { - Unable to control when far away from home } \\
\text { - Not following advice from healthcare providers }\end{array}$ & $\begin{array}{l}\text { - Patients } \\
\text { - Family caretakers }\end{array}$ \\
\hline
\end{tabular}

Challenges and obstacles in the provision of diabetes mellitus self-management education in the community (information obtained from HCPs)

The challenges and obstacles noted by HCPs in providing diabetes mellitus selfmanagement education (DMSE) at the community health centre are categorised into themes, as follows:

\section{Lack of skills in providing DMSE}

During the FGD process, some HCPs confirmed a lack of experience and some misunderstandings related to DSM practices. Some challenges related to providing DMSE to diabetes patients in the community were noted. For example, there was a lack of educational media to deliver information on DSM, whilst DMSE was provided using oneway teaching rather than counselling or participatory learning. Another HCP noted that they delivered the information and education every week without any evaluation forms to track the behavioural changes of patients after receiving the DMSE programme.

\section{Insufficient manpower}

Some HCPs mentioned that they spend a long time intensely working on administrative tasks at the community health centre. They also mentioned that they provide approximately 8 hours of treatment and care for hospitalised patients. Some of them also reported that they had to perform other jobs related to disease prevention and control in the community, such as providing child immunisation, tuberculosis control and communicable disease surveillance due to a limited number of HCPs. They also had to refer patients to the provincial hospital when an emergency requiring the further management of patients' symptoms occurs. The challenges and obstacles highlighted by the HCPs in providing DMSE to support the DSM of T2DM patients are summarised in Table 3. 
Table 3. Challenges and obstacles among HCPs in providing DMSE to support DSM.

\begin{tabular}{l|l} 
Themes & Sub-themes \\
\hline $\begin{array}{l}\text { Lack of problem-solving skills to deal with poor } \\
\text { diabetes management }\end{array}$ & $\begin{array}{l}\text { - Limited educational media and booklets } \\
\text { - One-way teaching of DMSE }\end{array}$ \\
\hline Insufficient manpower & $\begin{array}{l}\text { - High workload and job demands in the } \\
\text { community prevention and control programme } \\
\text { - Lack of confidence and experience in dealing with } \\
\text { diabetes management }\end{array}$ \\
\hline
\end{tabular}

\section{Discussion}

In this study, we determined how the unmet family function needs of T2DM patients cause impaired family function in supporting DMSM practices. Family members have an essential role in supporting DMSM practices through how they engage in behavioural change, increase communication skills, set goals, solve problems and influence patients' efforts. By using thematic analysis, we identified all of the unmet family function needs related to DMSM practices. Our findings provide valuable evidence regardless of family functioning's usefulness in supporting behavioural changes towards optimal T2DM self-management. Notably, previous studies have described the importance of the supportive and non-supportive actions of family in maintaining behaviours. ${ }^{10,27-29}$

Problem-solving skills are crucial for both patients and caretakers in dealing with DMSM practices. Lack of knowledge and skill are fundamental factors that prohibit families' critical thinking abilities when attempting to solve problems or enhance their problemsolving skills to support patients in their DMSM practices. Previous studies have revealed that problem-solving skill was related to dietary self-management behaviours, exercise patterns and psychosocial measures. ${ }^{30,31}$ Another study showed that problem-solving based DSM practices were sufficient to improve behaviour among lower-income patients. ${ }^{32}$

Successful diabetes management requires good teamwork between patients, caretakers and healthcare providers. Effective communication on DSM and sharing decision-making in diabetes care might impact treatment plans and health outcomes. Notably, poor communication has been associated with misconceptions related to diabetes management. ${ }^{10}$ Likewise, effective communication was shown to have a positive effect on improving patients' understanding and influencing self-management skills. ${ }^{33}$
Furthermore, the negative responses of family members can affect DMSM practices. The present study showed that family members were silent and discouraged patients from discussing their conditions. Moreover, a previous study showed that some patients tend to avoid expressing their needs due to the negative responses of family members, especially regarding eating behaviours and unhealthy lifestyle choices. ${ }^{19}$ Another study also reported that poor support from family members was associated with poor glycaemic control and health outcomes during the implementation of DMSM practices. ${ }^{34}$

Family involvement was a crucial aspect of maintaining DMSM practices. Patients who lacked emotional support often had poor relationships with their family members, especially their spouses. ${ }^{35}$ The same study also reported that family involvement in the DSM and glycaemic control of diabetic patients is essential. $^{34}$

Family and social support can predict healthpromoting behaviours and improve health outcomes among uncontrolled T2DM patients. A previous study revealed a positive correlation between social support and treatment adherence, with social support buffering patients' stress when living with a chronic illness such as diabetes. ${ }^{36}$ Another study also noted a positive correlation between optimal social support and self-care behaviour. Therefore, receiving sufficient support from family members can be a significant issue, which highlights the responsibility of family members in improving diabetes management. ${ }^{37}$ One notable barrier to diabetes care was the inaccessibility of a healthy diet and physical exercise when away from home. This challenge can impact the maintenance of healthy behaviours among uncontrolled T2DM patients. This study also confirmed a cause of unmet family function needs related to supporting DMSM practices: the inability to control patients' behaviours when they are 
away from home. Notably, both patients and their caretakers found it challenging to achieve the patients' blood glucose target.

Our results also contribute to understanding the complexity of family function. One obstacle to DMSM practices is that some determinants cannot be seen to have positive or negative effects. However, these are essential to consider within the community's sociocultural context. The potential aspect of leveraging family function aims to improve DMSM practices by helping family members understand their DMSM support roles. These roles include diet control as well as support in physical activity, medication taking, blood glucose monitoring, the prevention of diabetes risk complications and emotional support when facing stress related to the diabetes prognosis. It is important to note that family members should clarify their roles and functions to support T2DM patients in effectively managing diabetes according to the local situation and context of DMSM in communities.

\section{Strengths and Limitations}

This preliminary study is culturally explored from the perspectives of two Indonesian ethnicities in one province. We emphasised cultural information from the perspectives of T2DM patients, their families and HCPs during the data collection process by following the societies' local contexts and habits. Although the data were collected from different groups, the results cannot be generalised to explain the unmet family function needs of all diabetic patients in Indonesia. Moreover, the community perspective was not considered, which may affect the generalisation of these results to other communities.

\section{Implications for Practice}

The findings of this study suggest that HCPs at community health centres should involve family members in fully supporting T2DM patients in their DMSM practices. A group- based training with participatory learning and sharing experiences should be conducted among patient-caretaker dyads to strengthen family function and help patients in their daily life activities.

\section{Conclusion}

The findings of this study help to provide a better understanding of the context of family function in supporting patients in their DMSM practices. We also explored the unmet DMS support needs of patients, which including a lack of problem-solving skills for dealing with poor diabetes management, ineffective communication and refusal to share the burden of diabetes management, lack of affective responsiveness in encouraging patients' compliance, lack of affective involvement in diabetes management, insufficient family roles in supporting patients, poor behaviour control and insufficient family roles to support patients, and the inconsistent management of healthy behaviour during special occasions. HCPs should consider patients' needs and how best to support diabetic patients and their families. As such, an intervention that considers the cultural context of Indonesian communities is required.

\section{Acknowledgements}

The authors would like to thank the Ristekdikti for funding supporting this study. We also thank the community health centre staff from Polewali Mandar District for their valuable information related to diabetes management. We would also like to thank the family members who were willing to participate in this study.

\section{Conflicts of Interest}

We declare no conflicts of interest to publish this manuscript.

\section{Author Contributions}

$\mathrm{RAP}$ and $\mathrm{KC}$ designed the research and performed the conceptualisation, data collection, data analysis and writing of the original draft.

\section{References}

1. International Diabetes Federation [Internet] International Diabetes Federation-What is diabetes. Available from: https://www.idf.org/ about-diabetes/what-is-diabetes.html.
2. Pamungkas RA, Chamroonsawasdi K. $\mathrm{HbA1c}$ reduction and weight-loss outcomes: A systematic review and meta-analysis of community-based intervention trials among patients with type 2 diabetes mellitus. Int J Diabetes Dev Ctries. 2019; 39:394-407
3. Haas L, Maryniuk M, Beck J, et al. National standards for diabetes self-management education and support. Diabetes Care. 2012;35(11):2393-401. 
4. Pamungkas RA, Chamroonsawasdi K. Selfmanagement based coaching program to improve diabetes mellitus self-management practice and metabolic markers among uncontrolled type 2 diabetes mellitus in Indonesia: A quasi-experimental study. Diabetes Metab Syndr: Clin Res \& Rev. 2020;14(1):53-61.

5. Beanlands HM, Fox S, Howe A, et al. Caregiving by family and friends of adults receiving dialysis. Nephrol Nurs J. 2005;32(6):621-31.

6. Miller IW, Ryan CE, Keitner GI, et al. The McMaster approach to families: Theory, assessment, treatment and research. J Fam Ther. 2000;22:168-89.

7. Pamungkas RA, Chamroonsawasdi K, Vatanasomboon P, et al. Barriers to effective diabetes mellitus self-management (DMSM) practice for glycaemic uncontrolled type 2 diabetes mellitus (T2DM): A socio-cultural context of Indonesian communities in West Sulawesi. Eur J Investig Health Psychol Educ. 2019;10(1):250-61.

8. Mayberry LS, Osborn CY. Family support, medication adherence, and glycaemic control among adults with type 2 diabetes. Diabetes Care. Jun 2012;35(6):1239-45.

9. Manoogian MM, Harter LM, Denham SA. The storied nature of health legacies in the familial experience of type 2 diabetes. J Fam Commun. 2010;10:40-56.

10. Pamungkas R, Chamroonsawasdi $\mathrm{K}$, Vatanasomboon P. A systematic review: Family support integrated with diabetes self-management among uncontrolled type II diabetes mellitus patients. Behav Sci. 2017;7(4):62

11. Black S, Maitland C, Hilbers J, et al. Diabetes literacy and informal social support: A qualitative study of patients at a diabetes center. J Clin Nurs. 2017;26(1-2):248-57.

12. Dai L, Wang L. Review of family functioning Open J Soc Sci. 2015;03(12):134-41.

13. Olson DH. Circumplex model of marital and family systems. J Fam Ther. 2000;22:144-67.
14. Ryan CE, Epstein NB, Keitner GI, Miller IW, Bishop D. Evaluating and treating families: The McMaster Approach. Prim Care Companion J Clin Psychiatry. 2009; 11 (4):166

15. Ryan CE, Epstein NB, Keitner GI, et al. Evaluating and treating families: The McMaster Approach. New York: Routledge; 2005.

16. Vongmany J, Luckett T, Lam L, et al. Family behaviors that have an impact on the selfmanagement activities of adults living with type 2 diabetes: A systematic review and metasynthesis. Diabet Med. Feb 2018;35(2):184-94.

17. Wiebe DJ, Helgeson V, Berg CA. The social context of managing diabetes across the life span. Am Psychol. 2016;71:526-38.

18. Bennich BB, Røder ME, Overgaard D, et al. Supportive and non-supportive interactions in families with a type 2 diabetes patient: An integrative review. Diabetol Metab Syndr. 2017;9(57):1-9

19. Gunn KL, Seers K, Posner N, et al. 'Somebody there to watch over you': The role of the family in everyday and emergency diabetes care. Health Soc Care Community. 2012;20(6):591-8.

20. Isworo A, Ekowati W, Iskandar A, et al. Family involvement programmes on the metabolic response of diabetic patients. Health Sci J. 2018;12(2): 1-3

21. Pamungkas RA, Chamroonsawasdi K, Vatanasomboon P. Family functioning integrated with diabetes self-management: A concept analysis. Front Nurs. 2018;5(3):199-206.

22. Pamungkas RA, Chamroonsawasdi K. Family functional-based coaching program on healthy behavior for glycaemic control among Indonesian communities: A quasi-experimental study. Oman Med J. 2020;35(5):e173.

23. Grabowski D AT, Varming A, Ommundsen $\mathrm{CWI}$. Involvement of family members in life with type 2 diabetes: Six interconnected problem domains of significance for family health identity and healthcare authenticity. SAGE Open Med. 2017;5:1-9.

24. Puebla I, Aloudah NM, Scott NW, et al. Medication adherence among patients with type 2 diabetes: A mixed-methods study. PLoS One. 2018;13(12):1-18.
25. Mecleod J. Qualitative Research in Counseling and Psychotherapy: Second edition. London: SAGE Publications; 2011.

26. Saks M, Allsop J. Researching Health: Qualitative, Quantitative, and Mixed Methods. London: SAGE Publications; 2013.

27. Bennich BB, Roder ME, Overgaard D, et al. Supportive and non-supportive interactions in families with a type 2 diabetes patient: An integrative review. Diabetol Metab Syndr. 2017;9(57):1-9

28. Hu J, Wallace DC, McCoy TP, et al. A familybased diabetes intervention for Hispanic adults and their family members. Diabetes Educ. JanFeb 2014;40(1):48-59.

29. Rosland AM, Heisler M, Choi HJ, et al. Family influences on self-management among functionally independent adults with diabetes or heart failure: Do family members hinder as much as they help? Chronic Illn. Mar 2010;6(1):22-33.

30. Glasgow RE, Fisher L, Skaff M, et al. Problemsolving and diabetes self-management: Investigation in a large, multiracial sample. Diabetes Care. Jan 2007;30(1):33-7.

31. Pamungkas RA, Chamroonsawasdi K, Charupoonphol P, et al. A health-based coaching program for diabetes self-management practice: A sequential exploratory mixedmethod approach. Endocrinol Diabetes Nutr (Engl Ed). 2020; in press corrected proof

32. Hill-Briggs F, Lazo M, Peyrot M, et al. Effect of problem-solving-based diabetes selfmanagement training on diabetes control in a low income patient sample. J Gen Intern Med. 2011;26(9):972-8.

33. Heisler M, Bougnight RR, Hayward RA, et al. The relative importance of physician communication, participatory decision making, and patient understanding in diabetes self-management. J Gen Intern Med. 2002;17(4):243-52.

34. Baig AA, Benitez A, Quinn MT, et al. Family interventions to improve diabetes outcomes for adults. Ann NY Acad Sci. Sep 2015;1353(1):89-112. 
35. Jonathan G, Sandberg JRN, Bates T. Can couple level attachment mediate the influence of depressive symptoms on health? Am J Fam Ther. 2016;44(2):80-94.
36. Miller TA, Dimatteo MR. Importance of family/social support and impact on adherence to diabetic therapy. Diabetes Metab Syndr Obes. 2013;6:421-6.
37. Rad GS, Bakht, LA, Feizi A, et al. Importance of social support in diabetes care. J Educ Health Promot. 2013;2(62): doi: 10.4103/22779531.120864 